Article

\title{
One-Dimensional Chain-Type Dicopper Coordination Polymer Linked by 1,4-Di(4-pyridyl)benzene; Synthesis, Crystal Structure, Magnetic Property, and Gas-Adsorption Property
}

\author{
Natsumi Yano ${ }^{1}$, Makoto Handa ${ }^{1, *}$, Minoru Mitsumi ${ }^{2}$ and Yusuke Kataoka ${ }^{1, *}$ \\ 1 Department of Chemistry, Interdisciplinary Faculty of Science and Engineering, Shimane University, 1060, \\ Nishikawatsu, Matsue, Shimane 690-8504, Japan; s179802@matsu.shimane-u.ac.jp \\ 2 Department of Chemistry, Faculty of Science, Okayama University of Science, 1-1, Ridaicho, Kita-ku, \\ Okayama 700-0005, Japan; mitsumi@chem.ous.ac.jp \\ * Correspondence: handam@riko.shimane-u.ac.jp (M.H.); kataoka@riko.shimane-u.ac.jp (Y.K.); \\ Tel.: +81-852-32-6418 (M.H.); +81-852-32-6413 (Y.K.)
}

Received: 12 May 2018; Accepted: 8 June 2018; Published: 11 June 2018

\begin{abstract}
A one-dimensional chain-type dicopper(II) coordination polymer with 1,4-di(4-pyridyl)-benzene (dpybz), $\left[\mathrm{Cu}_{2}\left(\mathrm{O}_{2} \mathrm{C}-t \mathrm{Bu}\right)_{4}(\mathrm{dpybz})\right](\mathbf{1})$, is synthesized and characterized by single crystal $X$-ray diffraction, infrared spectroscopy, and CHN elemental analysis. Single crystal X-ray diffraction confirms that the one-dimensional chains of $\mathbf{1}$ are assembled with $\mathrm{CH} \cdots \pi$ interactions at the dpybz moieties to form a brick-like porous network structure. Magnetic susceptibility measurement and broken-symmetry density functional theory (BS-DFT) calculations indicate that (i) antiferromagnetic interactions are present between two copper ions through the bridging carboxylate ligands; the observed exchange integral value $(J)$ of 1 is $-175.3 \mathrm{~cm}^{-1}$, which is consistent with the DFT-calculated value for $\mathbf{1}\left(-174.5 \mathrm{~cm}^{-1}\right)$, and (ii) the magnetic interaction between two $\mathrm{Cu}_{2}$ units through the dpybz ligand is negligible. $\mathrm{N}_{2}$ adsorption measurements indicate that the porous structure of $\mathbf{1}$ is retained even after evacuation of the guest solvents from the pores of $\mathbf{1}$, and $\mathbf{1}$ adsorbs $\mathrm{N}_{2}$ molecules into its pores (the Langmuir surface area of $\mathbf{1}$ is estimated as $\left.538.0 \mathrm{~m}^{2} / \mathrm{g}\right)$.
\end{abstract}

Keywords: paddlewheel-type complex; dicopper complex; coordination polymer; magnetic property; density functional theory calculations

\section{Introduction}

A paddlewheel-type dicopper $\left(\mathrm{Cu}_{2}\right)$ unit bridged by four carboxylate $\left({ }^{-} \mathrm{O}_{2} \mathrm{C}-\mathrm{R}\right)$ ligands, $\left[\mathrm{Cu}_{2}\left(\mathrm{O}_{2} \mathrm{C}-\mathrm{R}\right)_{4}\right]$, is well known as an important molecular skeleton in the area of coordination chemistry [1-4], because it has been widely utilized as a secondary building block (SBU) for supra-molecular cages [5], coordination polymers (CPs) [6,7] and metal-organic frameworks (MOFs) [8,9]. Current synthetic strategies for $\left[\mathrm{Cu}_{2}\left(\mathrm{O}_{2} \mathrm{C}-\mathrm{R}\right)_{4}\right]$ SBU-based CPs and MOFs involve linking the $\mathrm{Cu}_{2}$ units though organic mono- or poly-carboxylate and diimine ligands $(\mathrm{N} \sim \mathrm{N})$ at the equatorial and axial positions of the $\mathrm{Cu}_{2}$ units, respectively [10,11]. For example, in 1995, Mikuriya et al. reported the synthesis and characterization of one-dimensional CPs $\left[\mathrm{Cu}_{2}\left(\mathrm{O}_{2} \mathrm{C}-t \mathrm{Bu}\right)_{4}(\mathrm{~N} \sim \mathrm{N})\right]$, in which $\left[\mathrm{Cu}_{2}\left(\mathrm{O}_{2} \mathrm{C}-t \mathrm{Bu}\right)_{4}\right]$ SBUs were linked by 1,4-diazabicyclo[2.2.2]octane (DABCO), pyrazine (pyz), and 4,4'-bipyridine (bpy) ligands [12]. These CPs are robust in air and occur in the crystalline state. The magnetic measurement of $\left[\mathrm{Cu}_{2}\left(\mathrm{O}_{2} \mathrm{C}-t \mathrm{Bu}\right)_{4}(\mathrm{pyz})\right]$ reveals an antiferromagnetic interaction $\left(J=-169.5 \mathrm{~cm}^{-1}, \mathrm{~g}=2.09\right)$ between two $\mathrm{Cu}$ ions through four bridging carboxylate ligands. Following 
this study, a one-dimensional $\mathrm{CP},\left[\mathrm{Cu}_{2}\left(\mathrm{O}_{2} \mathrm{C}-\mathrm{Ph}\right)_{4}(\mathrm{pyz})\right]$, was reported by Mori, Mikuriya, and Handa in 1999 [13]. In this CP, two phenyl groups of neighboring chains are stacked by non-covalent $\pi-\pi$ stacking interactions to give one-dimensional uniform channels, which are suitable for $\mathrm{N}_{2}$ gas adsorption. The channel structure in the $\mathrm{CP}$ is maintained, even after removal of the $\mathrm{CH}_{3} \mathrm{CN}$ crystallization solvent molecules from the crystal by drying the sample under vacuum. Since then, although there have been many reports on the synthesis and characterization of one-dimensional CPs, DABCO, pyz, bpy and their derivative linker ligands have been commonly used in combination with paddlewheel-type dicopper complexes [14-16]. Our research is now being directed to developing the chemistry of CPs with different types of linker ligands having enlarged molecular sizes with extended $\pi$-systems, and to investigating their (self-assembled) geometries, electronic structures and functional properties [17].

In this paper, we described the synthesis, characterization, and magnetic and gas-adsorption properties of one-dimensional $\mathrm{Cu}_{2} \mathrm{CPs}$ with 1,4-di(4-pyridyl)benzene (dpybz; see Figure 1) as an extended $\mathrm{N} \sim \mathrm{N}$ linker ligand, $\left[\mathrm{Cu}_{2}\left(\mathrm{O}_{2} \mathrm{C}-t \mathrm{Bu}\right)_{4}(\mathrm{dpybz})\right](\mathbf{1})$. To the best of our knowledge, this is the first example of a one-dimensional $\mathrm{Cu}_{2} \mathrm{CP}$ with the dpybz ligand. Interestingly, one-dimensional chains of $\mathbf{1}$ were assembled and stabilized with electrostatic $\mathrm{CH}-\pi$ interactions at the dpybz moieties; no such interaction was confirmed for CPs with pyz and bpy linkers. Density functional theory (DFT) calculations were performed to give a clear insight into the structural and electronic features affecting the magnetic properties of $\mathbf{1}$.

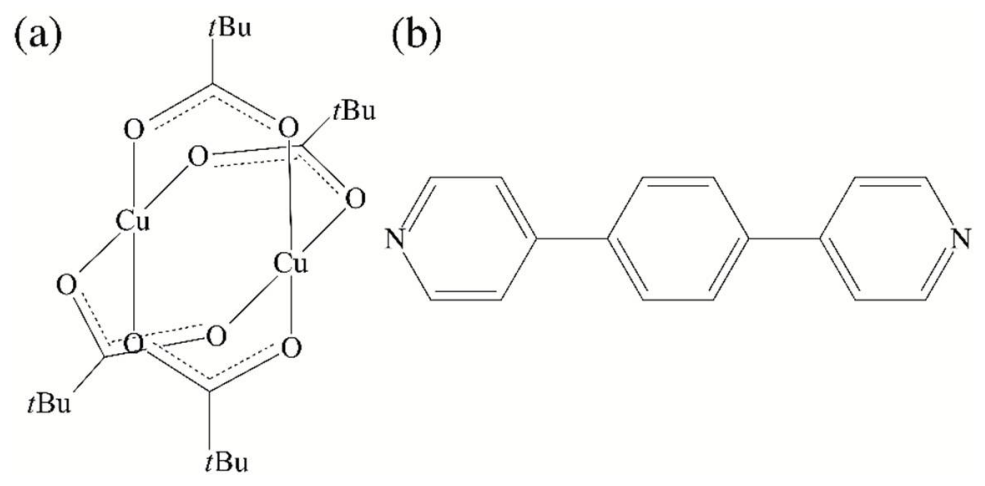

Figure 1. Molecular geometries of $(\mathbf{a})\left[\mathrm{Cu}_{2}\left(\mathrm{O}_{2} \mathrm{C}-\mathrm{tBu}\right)_{4}\right]$ and $(\mathbf{b})$ dpybz.

\section{Results and Discussion}

\subsection{Synthesis and Characterization of $\left[\mathrm{Cu}_{2}\left(\mathrm{O}_{2} \mathrm{C}-\mathrm{tBu}\right)_{4}(\mathrm{dpybz})\right](\mathbf{1})$}

Complex 1 was synthesized via a room temperature reaction between a tetrahydrofuran (THF) solution of $\left[\mathrm{Cu}_{2}\left(\mathrm{O}_{2} \mathrm{C}-t \mathrm{Bu}\right)_{4}\right]$ (see Figure $1 \mathrm{a}$ ) and a $N, N$-dimethylformamide (DMF) solution containing an equivalent amount of dpybz in an Erlenmeyer flask. Green crystals of 1 with a yield of $80.0 \%$, which are suitable for single crystal X-ray diffraction measurements, were deposited on the bottom of the flask after leaving the homogeneous reaction solution for 10 days. More detailed synthetic information concerning $\mathbf{1}$ is given in Section 3.5. Elemental analysis revealed that the crystalline powder of $\mathbf{1}$, which was obtained after heating at $353 \mathrm{~K}$ under vacuum for $3 \mathrm{~h}$, contained no crystallization solvent and was anhydrous. In the infrared spectrum (see Figure $\mathrm{S} 1$ ), a symmetric vibration $\left(v_{\mathrm{sym}}\right)$ and an asymmetric vibration $\left(v_{\text {asym }}\right)$ of the bridging carboxylate of 1 were observed at 1418 and $1607 \mathrm{~cm}^{-1}$, respectively, similar to those of $\left[\mathrm{Cu}_{2}\left(\mathrm{O}_{2} \mathrm{C}-t \mathrm{Bu}\right)_{4}\right]\left(v_{\mathrm{sym}}=1418 \mathrm{~cm}^{-1}, v_{\text {asym }}=1578 \mathrm{~cm}^{-1}\right)$, indicating that 1 possessed the paddlewheel-type $\mathrm{Cu}_{2}$ core as its SBU.

\subsection{Single Crystal X-ray Diffraction}

Single crystal X-ray diffraction for $\mathbf{1}$ was measured at $150 \mathrm{~K}$. The crystallographic data of $\mathbf{1}$ are summarized in Table S1 in the experimental section. The diffraction analysis revealed that $\mathbf{1}$ crystallized in the monoclinic system with a space group $C 2 / c$. The final refined structural model 
of 1 shows that an asymmetric unit of 1 contains one $\mathrm{Cu}^{2+}$ ion, two $\mathrm{O}_{2} \mathrm{C}-t \mathrm{Bu}$ anions, and one half of a dpybz ligand. This indicates that the crystallographic inversion centers of $\mathbf{1}$ were located at the midpoints of the paddlewheel-type $\mathrm{Cu}_{2}$ unit and the dpybz ligand. Selected bond distances and angles of $\mathbf{1}$ are summarized in Table S2 in the Supplementary Materials, and expanded and packing structures of $\mathbf{1}$ are shown in Figure 2. As shown in Figure 2a, the two Cu ions in $\mathbf{1}$ were coordinated by four $\mu$-carboxylate and one dpybz ligand. That is, $\mathbf{1}$ possessed the paddlewheel-type $\mathrm{Cu}_{2}$ core as its SBU, and the dpybz ligand coordinated to the axial sites of the paddlewheel-type $\mathrm{Cu}_{2}$ cores. The $\mathrm{Cu}$... Cu distance in the paddlewheel-type $\mathrm{Cu}_{2}$ units of 1 was 2.5938(6) $\AA$, which was close to the typical $\mathrm{Cu} \cdots \mathrm{Cu}$ distances of paddlewheel-type $\mathrm{Cu}_{2}$ complexes with analogous pyridyl ligands, such as $\left[\mathrm{Cu}_{2}\left(\mathrm{O}_{2} \mathrm{C}-\mathrm{Bu}\right)_{4}(\mathrm{pyz})\right](2.584(2) \AA)$, indicating that no direct $\mathrm{Cu}-\mathrm{Cu}$ bond is present between two $\mathrm{Cu}$ ions in $\mathbf{1}$ by judging from the similarity in the $\mathrm{Cu} \cdots \mathrm{Cu}$ distance between $\left[\mathrm{Cu}_{2}\left(\mathrm{O}_{2} \mathrm{C}-t \mathrm{Bu}\right)_{4}(\mathrm{pyz})\right]$ and 1 [12]. Thus, the primary coordination spheres of two $\mathrm{Cu}$ ions in $\mathbf{1}$ were in pentacoordinated environments with a square pyramidal structure. Expanding the structure of $\mathbf{1}$ showed an alternating arrangement of paddlewheel-type $\mathrm{Cu}_{2}$ units and dpybz ligands along the $\mathrm{Cu} \cdot \mathrm{Cu}$ vector, confirming a one-dimensional polymeric (chain) structure of $\mathbf{1}$. In the dpybz ligand of $\mathbf{1}$, two pyridyl rings at both ends of dpybz were located in a coplanar arrangement; the dihedral angles defined by the pyridyl rings were $0^{\circ}$, whereas both those defined by pyridyl and benzene rings within the dpybz ligand were $37.15^{\circ}$. The $\mathrm{Cu}-\mathrm{N}$ bond length in $\mathbf{1}$ was $2.156(2) \AA$, which was also comparable to that of $\left[\mathrm{Cu}_{2}\left(\mathrm{O}_{2} \mathrm{C}-t \mathrm{Bu}\right)_{4}(\mathrm{pyz})\right]$ (2.195(8) А) [12].
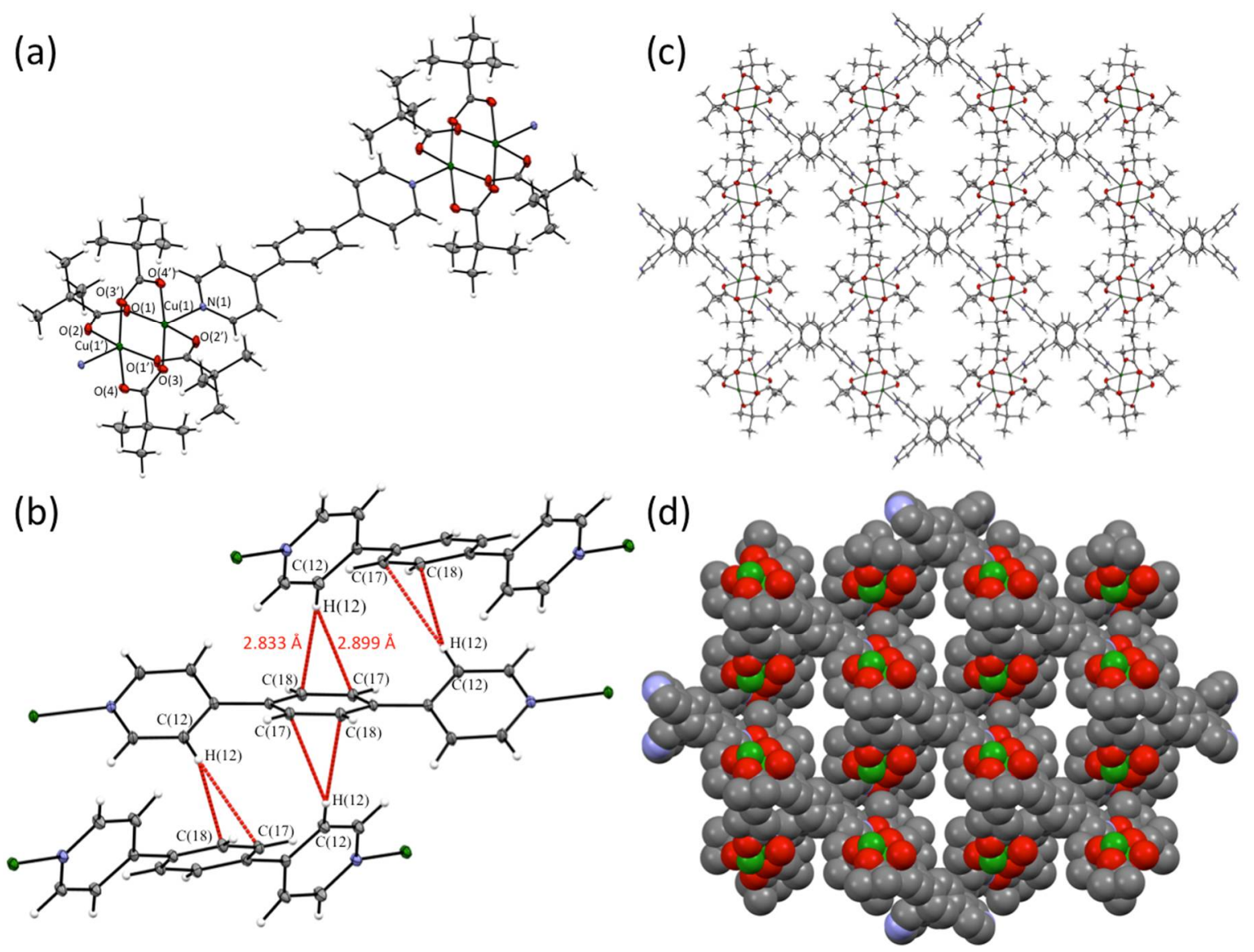

Figure 2. Crystal structure of 1. (a) Chain structure, (b) $\mathrm{CH}-\pi$ interactions of dpybz moieties, (c) packing view along $\mathrm{c}$ axis, and (d) CPK model of (c). Here, thermal ellipsoids of (a-c) are drawn with $20 \%$ probability. In (d), hydrogen atoms are omitted for clarity. Green: $\mathrm{Cu}$, Red: O, Gray: C, Blue: N, and White: $\mathrm{H}$. 
As shown in Figure 2c,d, the one-dimensional chains of $\mathbf{1}$ were assembled to form a brick-like porous network structure. Interestingly, the benzene moieties of dpybz ligands were arranged in a one-dimensional fashion along the $\mathrm{c}$ axis to form fourfold $\mathrm{CH}-\pi$ interactions with the upper and lower benzene moieties of dpybz ligands, as shown in Figure $1 \mathrm{~b}$. The $\mathrm{CH}(12) \cdots \pi$ (the midpoint of $\mathrm{C} 17$ and

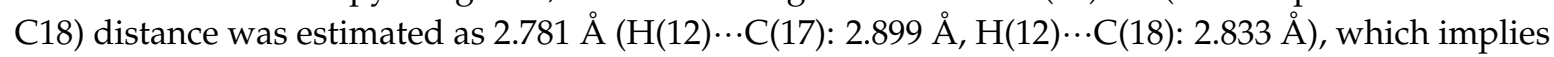
the existence of $\mathrm{CH}-\pi$ interactions [18]. Two DMF guest solvent molecules in $\mathbf{1}$ were disordered and their positions could not be determined. Thus, the PLATON SQUEEZE program was applied to estimate the void volume of $\mathbf{1}$ and to eliminate the residual electron density in the pores of $\mathbf{1}$ [19]. The solvent accessible void volume of $\mathbf{1}$ was estimated as $254.2 \AA^{3}$ per $\mathrm{Cu}_{2}$ unit, which is nearly the same as the sum of the volumes of two DMF molecules $\left(258 \AA^{3}\right)$. The void volume percentage of 1 was determined as $22.5 \%$. The channel-like pore diameter of $\mathbf{1}$ was $5.53 \times 5.05 \AA^{2}$ along the c axis, which is considered to be a preferable for gas adsorption.

\subsection{Magnetic Property of $\mathbf{1}$}

For 1, variable-temperature (VT) magnetic susceptibility measurement was performed with a SQUID magnetometer within the temperature range $(2-300 \mathrm{~K})$. As a comparison, the VT magnetic susceptibility of $\left[\mathrm{Cu}_{2}\left(\mathrm{O}_{2} \mathrm{C}-t \mathrm{Bu}\right)_{4}\right]$ was also measured. Figure 3 shows the molar magnetic susceptibilities $\left(\chi_{M}\right)$ and effective magnetic moments $\left(\mu_{\text {eff }}\right)$ (per $\mathrm{Cu}_{2}$ unit) of $\mathbf{1}$ and $\left[\mathrm{Cu}_{2}\left(\mathrm{O}_{2} \mathrm{C}-t \mathrm{Bu}\right)_{4}\right]$. At $300 \mathrm{~K}$, the $\chi_{\mathrm{M}}$ and $\mu_{\text {eff }}$ of $\mathbf{1}$ were $0.00143 \mathrm{emu} \mathrm{mol}{ }^{-1}$ and $1.85 \mu_{\mathrm{B}}$, respectively. The $\mu_{\mathrm{eff}}$ of $\mathbf{1}$ was within the typical range for paddlewheel-type $\mathrm{Cu}_{2}$ complexes $\left(1.6 \sim 1.9 \mu_{\mathrm{B}}\right)$ and slightly larger than that of $\left[\mathrm{Cu}_{2}\left(\mathrm{O}_{2} \mathrm{C}-t \mathrm{Bu}\right)_{4}\right]\left(1.76 \mu_{\mathrm{B}}\right)[12,13]$. When the temperature was decreased from $300 \mathrm{~K}$, the $\mu_{\text {eff }}$ decreased for both complexes, due to the antiferromagnetic interactions between the two $\mathrm{Cu}$ ions within the dinuclear molecules. The magnetic data for $\mathbf{1}$ and $\left[\mathrm{Cu}_{2}\left(\mathrm{O}_{2} \mathrm{C}-t \mathrm{Bu}\right)_{4}\right]$ were simulated using the Bleaney-Bowers equation:

$$
\chi_{\mathrm{M}}=2\left[(1-p)\left(N g^{2} \mu_{\mathrm{eff}}^{2} / k T\right)\{3+\exp (-2 J / k T)\}^{-1}+p\left(N g^{2} \mu_{\mathrm{eff}}{ }^{2} / 4 k T\right)+N \alpha\right]
$$

where $N$ is the Avogadro's number, $g$ is the spectroscopic splitting factor, $\beta$ is the Bohr magneton, $k$ is the Boltzmann constant, $J$ is the exchange integral between the copper(II) ions, $p$ is the paramagnetic mononuclear $\mathrm{Cu}(\mathrm{II})$ impurity constant, and $N \alpha$ is the temperature independent paramagnetism (TIP) [20]. The best fitting parameters, where $N \alpha$ was fixed at $60 \times 10^{-6} \mathrm{cgs} \mathrm{emu}$, are summarized in Table 1. The temperature-dependent profiles of magnetic susceptibilities and moments were well reproduced with the parameters for $\mathbf{1}$ and $\left[\mathrm{Cu}_{2}\left(\mathrm{O}_{2} \mathrm{C}-t \mathrm{Bu}\right)_{4}\right]$ (Figure 3), without considering the magnetic interaction between the dicopper(II) units. This means that the interaction through the linker ligand dpybz was negligible in 1 . A negligible interaction through the axial linker ligand, pyz, was also reported for $\left[\mathrm{Cu}_{2}\left(\mathrm{O}_{2} \mathrm{C}-t \mathrm{Bu}\right)_{4}(\mathrm{pyz})\right]$ and $\left[\mathrm{Cu}_{2}\left(\mathrm{O}_{2} \mathrm{C}-\mathrm{Ph}\right)_{4}(\mathrm{pyz})\right]$, and the estimated $J$ value of $-175.3 \mathrm{~cm}^{-1}$ for 1 was comparable to those for $\left[\mathrm{Cu}_{2}\left(\mathrm{O}_{2} \mathrm{C}-t \mathrm{Bu}\right)_{4}(\mathrm{pyz})\right]\left(\mathrm{J}=-183 \mathrm{~cm}^{-1}\right)$ and $\left[\mathrm{Cu}_{2}\left(\mathrm{O}_{2} \mathrm{C}-\mathrm{Ph}\right)_{4}(\mathrm{pyz})\right]$ $\left(J=-169.5 \mathrm{~cm}^{-1}\right)[12,13]$. The $J$ value of $\mathbf{1}\left(-175.3 \mathrm{~cm}^{-1}\right)$ was smaller than that of $\left[\mathrm{Cu}_{2}\left(\mathrm{O}_{2} \mathrm{C}-t \mathrm{Bu}\right)_{4}\right]$ $\left(J=-201.4 \mathrm{~cm}^{-1}\right)$, which was theoretically interpreted using DFT calculations (See Section 2.4).

Table 1. Best fitting magnetic parameters of $\mathbf{1}$ and $\left[\mathrm{Cu}_{2}\left(\mathrm{O}_{2} \mathrm{C}-t \mathrm{Bu}\right)_{4}\right]$.

\begin{tabular}{ccc}
\hline Magnetic Parameters & $\mathbf{1}$ & {$\left[\mathbf{C u}_{\mathbf{2}}\left(\mathbf{O}_{\mathbf{2}} \mathbf{C}-t \mathbf{B u}\right)_{\mathbf{4}}\right]$} \\
\hline$J\left(\mathrm{~cm}^{-1}\right)$ & -175.3 & -201.4 \\
$g$ & 2.09 & 2.17 \\
$N \alpha\left(\mathrm{cm}^{3} \mathrm{~mol}^{-1}\right)$ & $60 \times 10^{-6}$ & $60 \times 10^{-6}$ \\
$p$ & 0.0039 & 0.00088 \\
${ }^{a} R / 10^{4}$ & 4.41 & 3.76 \\
\hline \multicolumn{3}{c}{}
\end{tabular}


(a)

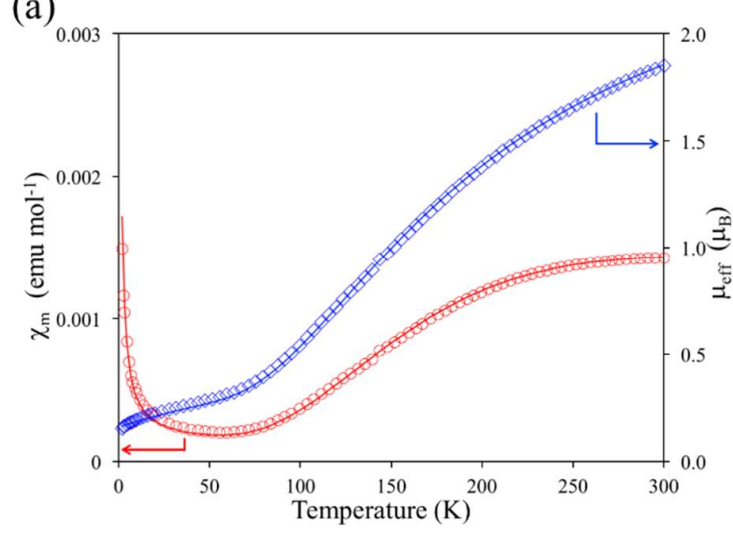

(b)

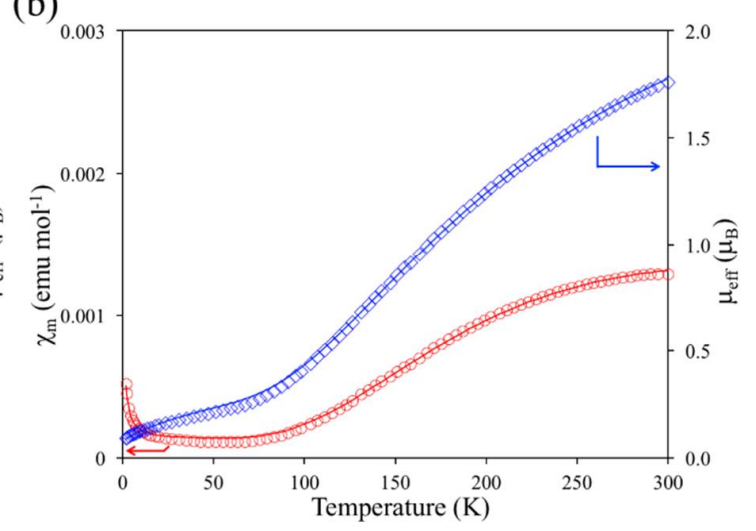

Figure 3. Magnetic susceptibilities $\left(\chi_{\mathrm{M}}: \bigcirc\right)$ and effective magnetic moments $\left(\mu_{\mathrm{eff}}: \diamond\right)$ of $(\mathbf{a}) \mathbf{1}$ and (b) $\left[\mathrm{Cu}_{2}\left(\mathrm{O}_{2} \mathrm{C}-t \mathrm{Bu}\right)_{4}\right]$. Solid lines are drawn with parameter values described in the text.

\subsection{Results of Theoretical Calculations}

To investigate the thermodynamically favorable spin states, electronic structures, spin density distributions and magnetic properties of $\mathbf{1}$, broken-symmetry density functional theory (BS-DFT) calculations were performed on model structures of $\mathbf{1}$, which were obtained from crystal structures of 1. Here, $\left[\mathrm{Cu}_{2}\left(\mathrm{O}_{2} \mathrm{C}-\mathrm{tBu}\right)_{4}\right]$ was also calculated for comparison. Single point energy calculations revealed that the singlet spin states of $\mathbf{1}$ and $\left[\mathrm{Cu}_{2}\left(\mathrm{O}_{2} \mathrm{C}-\mathrm{tBu}\right)_{4}\right]$ were 0.503 and $0.619 \mathrm{kcal} / \mathrm{mol}$, which were more stable than their triplet spin states, indicating that 1 and $\left[\mathrm{Cu}_{2}\left(\mathrm{O}_{2} \mathrm{C}-t \mathrm{Bu}\right)_{4}\right]$ showed antiferromagnetic coupling between the two magnetic centers in $\mathbf{1}$ and $\left[\mathrm{Cu}_{2}\left(\mathrm{O}_{2} \mathrm{C}-t \mathrm{Bu}\right)_{4}\right]$. In fact, the calculated $J$ values of $\mathbf{1}$ and $\left[\mathrm{Cu}_{2}\left(\mathrm{O}_{2} \mathrm{C}-\mathrm{tBu}\right)_{4}\right]$, which were estimated by an approximate spin-projection (AP) scheme developed by Yamaguchi's group [21], were -174.5 and $-214.2 \mathrm{~cm}^{-1}$, respectively. These are consistent with the experimental values for $\mathbf{1}$ and $\left[\mathrm{Cu}_{2}\left(\mathrm{O}_{2} \mathrm{C}-t \mathrm{Bu}\right)_{4}\right]$ and are clear evidence of the antiferromagnetic interaction in 1 and $\left[\mathrm{Cu}_{2}\left(\mathrm{O}_{2} \mathrm{C}-t \mathrm{Bu}\right)_{4}\right]$. The origin of the antiferromagnetic coupling interactions in 1 and $\left[\mathrm{Cu}_{2}\left(\mathrm{O}_{2} \mathrm{C}-t \mathrm{Bu}\right)_{4}\right]$ were further investigated with respect to the spin density distributions. As shown in Figure 4, the spin density distributions of $\mathbf{1}$ and $\left[\mathrm{Cu}_{2}\left(\mathrm{O}_{2} \mathrm{C}-t \mathrm{Bu}\right)_{4}\right]$ in the singlet and triplet spin states are commonly localized on the $\left[\mathrm{Cu}_{2}\left(\mathrm{O}_{2} \mathrm{C}-\mathrm{tBu}\right)_{4}\right]$ unit, and the singlet and triplet spin states differ only by the phases of the $\mathrm{dx}^{2}-\mathrm{y}^{2}$ orbitals of the $\mathrm{Cu}$ ions. Moreover, the spin densities of the dpybz moieties were negligible. The calculated results are summarized: (i) an antiferromagnetic interaction occurred in 1 between unpaired electrons residing in $\mathrm{dx}^{2}-\mathrm{y}^{2}$ orbitals of $\mathrm{Cu}$ ions via a super-exchange mechanism through four bridging carboxylate ligands, and (ii) the magnetic interaction between two $\mathrm{Cu}_{2}$ units through the dpybz ligand was negligible.

Additionally, the formation of interchain $\mathrm{CH}-\pi$ interactions in the crystal structure of $\mathbf{1}$ was confirmed by long-range and dispersion corrected density functional theory (LC-DFT-D; B3LYP-D2 functional). Figure S2 shows the calculated models of two dpybz moieties, which were obtained from the crystal structure of $\mathbf{1}$. The counterpoise method afforded an electrostatic interaction energy of $-10.46 \mathrm{kcal} / \mathrm{mol}(-5.23 \mathrm{kcal} / \mathrm{mol}$ per $\mathrm{CH}-\pi$ interaction). This confirmed that two-fold $\mathrm{CH}-\pi$ interactions were formed between two dpybz ligands, and these were stronger than typical $\mathrm{CH}-\pi$ interactions. 

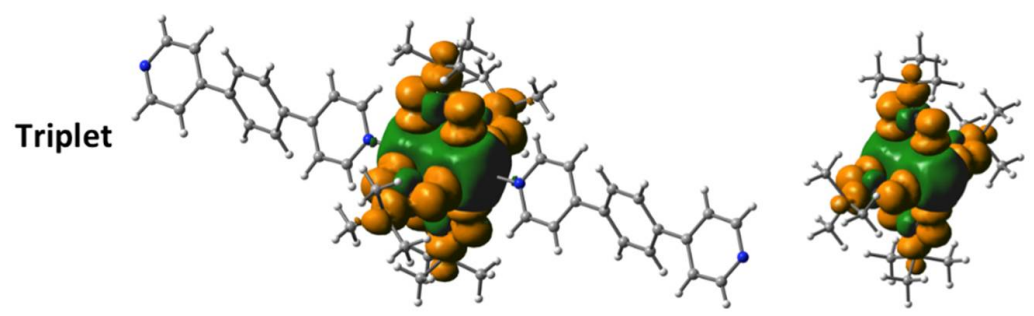

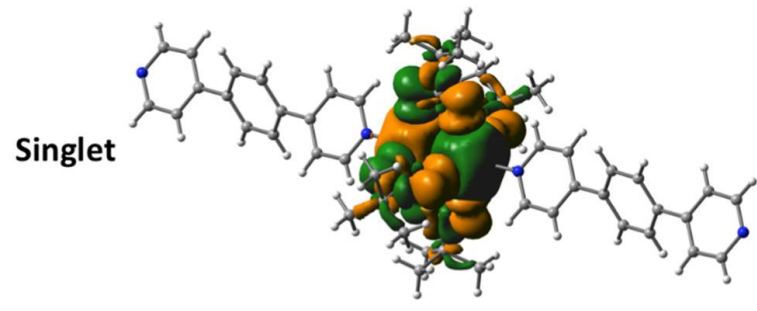

1

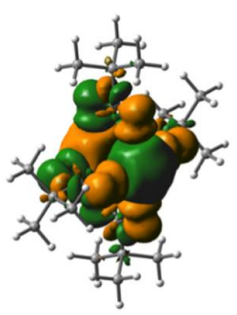

$\left[\mathrm{Cu}_{2}\left(\mathrm{O}_{2} \mathrm{C}-\mathrm{tBu}\right)_{4}\right]$

Figure 4. Spin density distributions of model structures of $\mathbf{1}$ and $\left[\mathrm{Cu}_{2}\left(\mathrm{O}_{2} \mathrm{C}-t \mathrm{Bu}\right)_{4}\right]$ (optimized geometry at a singlet state) calculated by the UCAM-B3LYP method (basis sets: TZVP for Cu atom and 6-31+G* for other atoms).

\subsection{Nitrogen Adsorption Properties}

Finally, to evaluate the porosity of $\mathbf{1}$, the nitrogen adsorption isotherm was measured at $77.4 \mathrm{~K}$. As shown in Figure 5, 1 strongly adsorbed $\mathrm{N}_{2}$ gases at a low relative pressure $\left(\mathrm{P} / \mathrm{P}_{0}<0.2\right)$, and an arched adsorption isotherm was obtained. This type of the isotherm plot is frequently observed in physical $\mathrm{N}_{2}$ adsorption of porous materials with micro- and subnano-pores [22] and can be classified as an IUPAC-I type isotherm. At a relative pressure of $0.3, \mathrm{~N}_{2}$ gas was moderately adsorbed on the surface of $\mathbf{1}$, as with typical CPs and MOFs. The Langmuir and BET surface areas of $\mathbf{1}$ were estimated as 538.0 and $400.5 \mathrm{~m}^{2} / \mathrm{g}$, respectively, indicating that 1 had permanent porosity even after evacuation of guest solvents from its pores. The surface area of $\mathbf{1}$ was relatively higher in one-dimensional CPs.

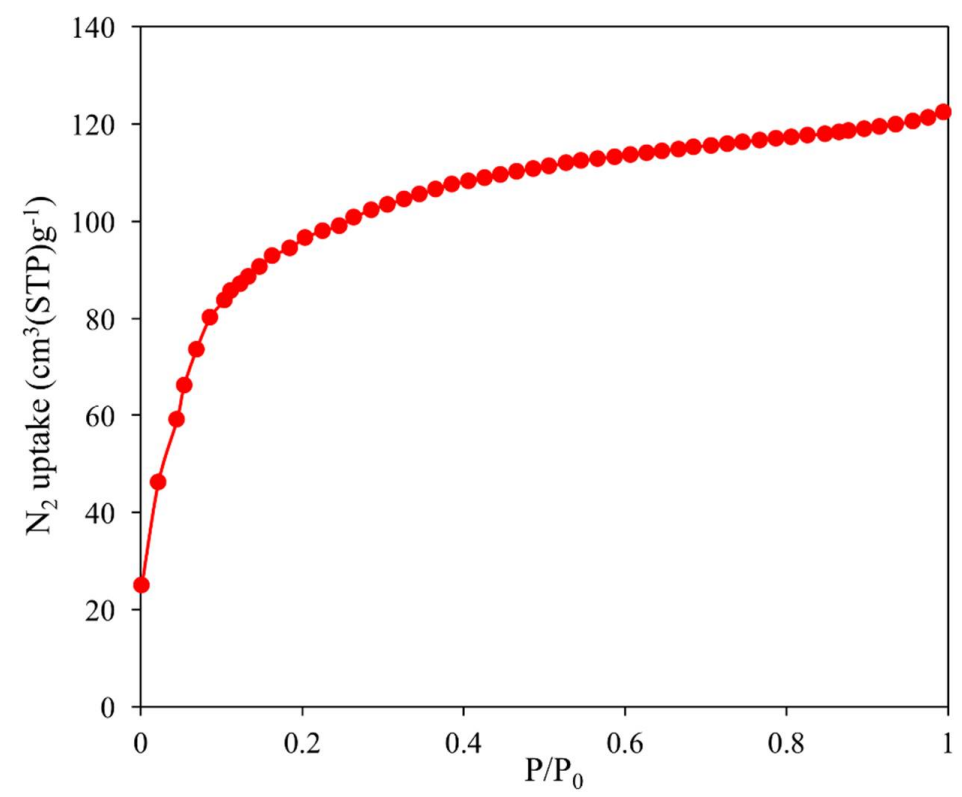

Figure 5. Nitrogen adsorption isotherm of $\mathbf{1}$ at $77.4 \mathrm{~K}$. 


\section{Materials and Methods}

\subsection{General}

All chemicals and solvents used in this study were purchased from commercial suppliers and were used without further purification. Fourier transform infrared (FT-IR) spectra were recorded on a JASCO FT-IR 4600 spectrophotometer using KBr pallets. Elemental analysis was conducted with a Yanaco CHN Corder MT-6 instrument. The dependence of the magnetic susceptibility on the temperature was determined using a Quantum Design MPMS magnetometer at 5000 Oe from 2 to $300 \mathrm{~K}$. The nitrogen adsorption isotherm of $\mathbf{1}$ was measured at $77.4 \mathrm{~K}$ with a MicrotracBEL BELSORP-mini II analyzer.

\subsection{Single Crystal X-ray Diffraction}

Single crystals suitable for single crystal X-ray diffraction were obtained by using the method described in Section 3.5. A crystal of $\mathbf{1}$ was coated in Parabar oil to protect it from moisture, mounted on a CryoLoop and placed on a goniometer head. X-ray diffraction data for $\mathbf{1}$ were collected at $150 \mathrm{~K}$ on a RIGAKU Mercury 70 CCD system equipped with a rotating anode X-ray generator with monochromated Mo-K $\alpha$ radiation $(\lambda=0.71075 \AA)$. Diffraction data for 1 were processed using the CrystalClear-SM program (RIGAKU). The structure of 1 was initially solved with a direct method (SIR-2011) [23] and refined using the full-matrix least-squares technique $\mathrm{F}^{2}$ with SHELXL-2014 [24] in the CrystalStructure 4.2.5 software (RIGAKU). Non-hydrogen atoms were refined with anisotropic displacement parameters, and hydrogen atoms were located in the calculated positions and refined using riding models. The residual electron densities in the void space of the final refined structure of 1 were evaluated using the PLATON SQUEEZE program [18]. The crystal data can be obtained as Crystallographic information file (CIF) from the Cambridge Crystallographic Data Center (CCDC). The deposition number of $\mathbf{1}$ was 1841609.

\subsection{Theoretical Calculation}

The BS-DFT calculations performed in this study were carried out with a long-range corrected uCAM-B3LYP functional [25] combined with the TZVP basis set for $\mathrm{Cu}$ and $6-31+\mathrm{G}^{*}$ for other atoms in the Gaussian 09 program [26]. The geometry of the calculated model of $\mathbf{1}$ was obtained from its crystal structure, while that of $\left[\mathrm{Cu}_{2}\left(\mathrm{O}_{2} \mathrm{C}-t \mathrm{Bu}\right)_{4}\right]$ was obtained by full geometry optimization in the singlet state. The exchange integral $(J)$ was estimated by the AP scheme (known as the Yamaguchi equation; see Scheme 2) developed by Yamaguchi's group [21]:

$$
J=\frac{E_{\text {singlet }}-E_{\text {triplet }}}{\left\langle S^{2}\right\rangle_{\text {singlet }}-\left\langle S^{2}\right\rangle_{\text {triplet }}}
$$

where $\mathrm{E}$ and $\left\langle\mathrm{S}^{2}\right\rangle$ are the total energy and total angular momentum, respectively. The interchain $\mathrm{CH}-\pi$ interaction in the crystal structure of 1 was evaluated with the long-range and dispersion corrected CAM-B3LYP-D2 functional combined with the $6-31+\mathrm{G}^{*}$ basis set. Here, the counterpoise method was applied to estimate the energies of the $\mathrm{CH}-\pi$ interaction. Spin density distributions were drawn using the GaussView program.

\subsection{Synthesis of $\left[\mathrm{Cu}_{2}\left(\mathrm{O}_{2} \mathrm{C}-t \mathrm{Bu}\right)_{4}\right]$}

$\left[\mathrm{Cu}_{2}\left(\mathrm{O}_{2} \mathrm{C}-t \mathrm{Bu}\right)_{4}\right]$ was prepared by a literature method with slight modifications [27]. A mixture of $\left[\mathrm{Cu}_{2}\left(\mathrm{O}_{2} \mathrm{CCH}_{3}\right)_{4}\left(\mathrm{H}_{2} \mathrm{O}\right)_{2}\right](159.8 \mathrm{mg}, 0.400 \mathrm{mmol})$ and pivalic acid $(5.0 \mathrm{~mL}, 0.044 \mathrm{~mol}) \mathrm{in} \mathrm{EtOH}(30.0 \mathrm{~mL})$ was heated at $323 \mathrm{~K}$ for $2 \mathrm{~h}$. The resulting solution was evaporated to dryness, and its residue was collected on a membrane filter and washed with hexane. The obtained blue powder was dried under vacuum at $353 \mathrm{~K}$ for $3 \mathrm{~h}$. $\left[\mathrm{Cu}_{2}\left(\mathrm{O}_{2} \mathrm{C}-\mathrm{tBu}\right)_{4}\right]$ was obtained as a crystalline blue powder in $79.9 \%(170.0 \mathrm{mg})$ 
yield. Anal. Calcd for $\mathrm{C}_{20} \mathrm{H}_{36} \mathrm{Cu}_{2} \mathrm{O}_{8}$ : C, 45.19; H, 6.83\%. Found: C, 45.19; H, 6.67\%. IR data (KBr disk, $\mathrm{cm}^{-1}$ ): $1578(\mathrm{~s}), 1529(\mathrm{w}), 1484(\mathrm{w}), 1418(\mathrm{~m}), 1377(\mathrm{w}), 1362(\mathrm{w}), 1226(\mathrm{~m}), 897(\mathrm{w}), 786(\mathrm{w})$ and $624(\mathrm{vw})$.

\subsection{Synthesis of $\left[\mathrm{Cu}_{2}\left(\mathrm{O}_{2} \mathrm{C}-\mathrm{tBu}\right)_{4}(\mathrm{dpybz})\right](\mathbf{1})$}

A THF solution $(7.0 \mathrm{~mL})$ of $\left[\mathrm{Cu}_{2}\left(\mathrm{O}_{2} \mathrm{C}-\mathrm{BBu}\right)_{4}\right](79.7 \mathrm{mg}, 0.15 \mathrm{mmol})$ and a DMF solution $(10.0 \mathrm{~mL})$ of dpybz (34.8 mg, $0.15 \mathrm{mmol}$ ) were mixed and left for 10 days at room temperature. The single crystals deposited at the bottom of the flask were collected on a membrane filter, washed with DMF and diethylether, and finally dried at $353 \mathrm{~K}$ under vacuum for $3 \mathrm{~h}$. 1 was obtained as a crystalline green powder in 80.0\% (89.8 mg) yield. Anal. Calcd for $\mathrm{C}_{36} \mathrm{H}_{48} \mathrm{Cu}_{2} \mathrm{~N}_{2} \mathrm{O}_{8}$ : C, 56.61; $\mathrm{H}, 6.33 ; \mathrm{N}, 3.67 \%$. Found: C, 56.86; H, 6.09; N, 3.88\%. IR data (KBr disk, $\left.\mathrm{cm}^{-1}\right): 2958(\mathrm{~m}), 2926(\mathrm{w}), 2871$ (w), 1617 (s), $1607(\mathrm{~s}), 1483(\mathrm{~m}), 1418(\mathrm{~m}), 1376(\mathrm{w}), 1361(\mathrm{w}), 1226(\mathrm{~m}), 810(\mathrm{w}), 789(\mathrm{w}), 717(\mathrm{w})$ and $619(\mathrm{w})$.

\section{Conclusions}

In conclusion, we investigated the synthesis, crystal structure, and magnetic and gas-adsorption properties of a one-dimensional chain-type $\mathrm{Cu}_{2}$ coordination polymer, $\mathbf{1}$, by means of experimental and theoretical techniques. Single crystal X-ray diffraction revealed that (i) the $\left[\mathrm{Cu}_{2}\left(\mathrm{O}_{2} \mathrm{C}-\mathrm{tBu}\right)_{4}\right] \mathrm{SBU}$ and dpybz ligand were alternately arranged to create the one-dimensional chain-type structure of $\mathbf{1}$, and (ii) interchain $\mathrm{CH}-\pi$ interactions of the dpybz moieties of $\mathbf{1}$ played an important role in forming the self-assembled brick-like porous network structures of 1 . From these results, enlarging the planarity of dpybz was considered to stabilize the self-assembled structures of CPs and MOFs via electrostatic interactions. Magnetic analyses and DFT calculations confirmed that antiferromagnetic interactions were present between the two $\mathrm{Cu}$ ions through bridging carboxylate ligands, and that the magnetic interaction between two $\mathrm{Cu}_{2}$ units through the dpybz ligand was negligible. The $\mathrm{N}_{2}$ adsorption measurements confirmed that the porous network structure of $\mathbf{1}$ was maintained even after evacuation of guest solvent molecules from its pores, and $\mathbf{1}$ adsorbed a suitable amount of $\mathrm{N}_{2}$ gas into its pores. Thus, $\mathbf{1}$ is an exceptional example of a robust porous network CP, which is maintained by electrostatic $\mathrm{CH}-\pi$ interactions.

Supplementary Materials: The following are available online at http:/ /www.mdpi.com/2312-7481/4/2/26/s1. Figure S1: IR spectrum of 1 (in $\mathrm{KBr}$ ) at $300 \mathrm{~K}$. Figure S2: Calculated model structures of two dpybz ligands. Table S1: Crystallographic data of $\mathbf{1}$. Table S2: Selected bond lengths $(\AA)$ and angles $\left({ }^{\circ}\right)$ of the crystal structure of 1 .

Author Contributions: N.Y. performed the experiments and wrote the paper; M.H. analyzed the data; M.M. contributed analysis tools and performed the gas-adsorption experiments; Y.K. conceived and designed the experiments, analyzed the data and wrote the paper.

Funding: This work was partially supported by Grant-in-Aid for Scientific Research Nos. 15K17897, 16K05722, and 17J11019 from the Ministry of Education, Culture, Sports, Science and Technology (MEXT), Japan.

Acknowledgments: N.Y. acknowledges Research Fellowships of Japan Society for the Promotion of Science for Young Scientists.

Conflicts of Interest: The authors declare no conflicts of interest.

\section{References}

1. Van Nierkert, J.N.; Schoening, F.R.L. X-ray Evidence for Metal-toMetal Bonds in Cupric and Chromous Acetate. Nature 1953, 171, 6834-6859. [CrossRef]

2. Melnik, M. Study of the relation between the structural data and magnetic interaction in oxo-bridged binuclear copper(II) compounds. Coord. Chem. Rev. 1982, 42, 259-293. [CrossRef]

3. Kato, M.; Muto, Y. Factors affecting the magnetic properties of dimeric copper(II) complexes. Coord. Chem. Rev. 1988, 92, 45-83. [CrossRef] 
4. Köberl, M.; Cokoja, M.; Herrmann, W.A.; Kühn, F.E. From molecules to materials: Molecular paddle-wheel synthons of macromolecules, cage compounds and metal-organic frameworks. Dalton Trans. 2011, 40, 6834-6859. [CrossRef] [PubMed]

5. Eddaoudi, M.; Kim, J.; Wachter, J.B.; Chae, H.K.; O'Keeffe, M.; Yaghi, O.M. Porous Metal-Organic Polyhedra: $25 \AA$ Cuboctahedron Constructed from $12 \mathrm{Cu}_{2}\left(\mathrm{CO}_{2}\right)_{4}$ Paddle-Wheel Building Blocks. J. Am. Chem. Soc. 2001, 123, 4368-4369. [CrossRef] [PubMed]

6. Rao, V.M.; Sathyanarayana, D.N.; Manohar, H. X-ray crystal structures of somo adducts of dimeric copper(II) acetate. Nature of the copper-copper interaction. J. Chem. Soc. Dalton Trans. 1983, 0, 2167-2173. [CrossRef]

7. Horikoshi, R.; Mikuriya, M. One-Dimensional Coordination Polymers from the Self-Assembly of Copper(II) Carboxylates and 4,4'-Dithiobis(pyridine). Bull. Chem. Soc. Jpn. 2005, 78, 827-834. [CrossRef]

8. Mori, W.; Inoue, F.; Yoshida, K.; Nakayama, H.; Takamizawa, S.; Kishita, M. Synthesis of New Adsorbent Copper(II) Terephthalate. Chem. Lett. 1997, 26, 1219-1220. [CrossRef]

9. Chui, S.S.-Y.; Lo, S.M.-F.; Charmant, J.P.H.; Orpen, A.G.; Williams, I.D. A Chemically Functionalizable Nanoporous Material $\left[\mathrm{Cu}_{3}(\mathrm{TMA})_{2}\left(\mathrm{H}_{2} \mathrm{O}\right)_{3}\right]_{\mathrm{n}}$. Science 1999, 283, 1148-1150. [CrossRef] [PubMed]

10. Seki, K.; Takamizawa, S.; Mori, W. Design and Gas Adsorption Property of a Three-Dimensional Coordination Polymer with a Stable and Highly Porous Framework. Chem. Lett. 2001, 30, 332-333. [CrossRef]

11. Ohmura, T.; Usuki, A.; Fukumori, K.; Ohta, T.; Ito, M.; Tatsumi, K. New-Porphyrin-Based Metal-Organic Framework with High Porosity: 2-D Infinite 22.2 Å Square-Grid Coordination Network. Inorg. Chem. 2006, 45, 7988-7990. [CrossRef] [PubMed]

12. Mikuriya, M.; Nukada, R.; Morishita, H.; Handa, M. Chain Compounds Formed by the Reaction of Copper(II) Carboxylate $\left[\mathrm{Cu}_{2}\left(\mathrm{O}_{2} \mathrm{CR}\right)_{4}\right]\left(\mathrm{R}=\mathrm{C}\left(\mathrm{CH}_{3}\right)_{3}, \mathrm{CCl}_{3}\right)$ and Bridging Ligand $\mathrm{L}$ ( $\mathrm{L}=$ Pyrazine, 4,4'-Bipyridine, and 1,4-Diazabicyclo[2,2,2]octane). Chem. Lett. 1995, 24, 617-618. [CrossRef]

13. Nukada, R.; Mori, W.; Takamizawa, S.; Mikuriya, M.; Handa, M.; Naono, H. Microporous Structure of a Chain Compound of Copper(II) Benzoate Bridged by Pyrazine. Chem. Lett. 1999, 28, 367-368. [CrossRef]

14. Takahashi, K.; Hishino, N.; Takeda, T.; Noro, S.; Nakamura, T.; Takeda, S.; Akutagawa, T. Structural Flexibilities and Gas Adsorption Properties of One-Dimensional Copper(II) Polymers with Paddle-Wheel Units by Modification of Benzoate Ligands. Inorg. Chem. 2015, 54, 9423-9431. [CrossRef] [PubMed]

15. Hwang, I.J.; Jo, Y.D.; Kim, H.; Kim, K.B.; Jung, K.-D.; Kim, C.; Kim, Y.; Kim, S.-J. Catalytic transesterification reactions of one-dimensional coordination polymers containing paddle-wheel-type units connected by various bridging ligands. Inorg. Chim. Acta 2013, 402, 39-45. [CrossRef]

16. Liu, C.-S.; Wang, J.-J.; Yan, L.-F.; Chang, Z.; Bu, X.-H.; Sañudo, E.C.; Ribas, J. Copper(II), Cobalt(II), and Nickel(II) Complexes with a Bulky Anthracene-Based Carboxylate Ligand: Syntehsis, Crystal Structures, and Magnetic Properties. Inorg. Chem. 2007, 46, 6299-6310. [CrossRef] [PubMed]

17. Kataoka, Y.; Yano, N.; Shimodaira, T.; Yan, Y.-N.; Yamasaki, M.; Tanaka, H.; Omata, K.; Kawamoto, T.; Handa, M. Paddlewheel-Type Dirhodium Tetrapivalate Based Coordination Polymer: Synthesis, Characterization, and Self-Assembly and Disassembly Transformation Properties. Eur. J. Inorg. Chem. 2016, 17, 2810-2815. [CrossRef]

18. Tsuzuki, S.; Fujii, A. Nature and physical origin of $\mathrm{CH} / \pi$ interaction: Significant difference from conventional hydrogen bonds. Phys. Chem. Chem. Phys. 2008, 19, 2584-2594. [CrossRef] [PubMed]

19. Spek, A.L. Structure validation in chemical crystallography. Acta Crystallogr. 2009, D65, 148-155. [CrossRef] [PubMed]

20. Bleaney, B.; Bowers, K.D. Anomalous paramagnetism of copper acetate. Proc. R. Soc. A 1952, 214, 451-465. [CrossRef]

21. Yamaguchi, K.; Tsunekawa, T.; Yoyoda, Y.; Fueno, T. Ab initio molecular orbital calculations of effective exchange integrals between transition metal ions. Chem. Phys. Lett. 1988, 143, 371-376. [CrossRef]

22. An, J.; Fiorella, R.P.; Geib, S.J.; Rosi, N.L. Synthesis, Structure, Assembly, and Modulation of the $\mathrm{CO}_{2}$ Adsorption Properties of a Zinc-Adeninate Macrocycle. J. Am. Chem. Soc. 2009, 131, 8401-8403. [CrossRef] [PubMed]

23. Buria, M.C.; Caliandro, R.; Camalli, M.; Carrozzini, B.; Cascarano, G.L.; Giacovazzo, C.; Mallamo, M.; Mazzone, A.; Polodori, G.; Spagna, R. SIR2011: A new package for crystal structure determination and refinement. J. Appl. Cryst. 2012, 45, 357-361. 
24. Sheldrick, G.M. Crystal structure refinement with SHELXL. Acta Crystallogr. 2015, C71, 3-8. [CrossRef]

25. Yanai, T.; Tew, D.P.; Handy, N.C. A new hybrid exchange-correlation functional using the Coulomb-attenuating method (CAM-B3LYP). Chem. Phys. Lett. 2004, 393, 51-57. [CrossRef]

26. Frisch, M.J.; Trucks, G.W.; Schlegel, H.B.; Scuseria, G.E.; Robb, M.A.; Cheeseman, J.R.; Scalmani, G.; Barone, V.; Mennucci, B.; Petersson, G.A.; et al. Gaussian 09, Revision C.01; Gaussian, Inc.: Wallingford, CT, USA, 2009.

27. Muto, Y.; Hirashima, N.; Tokii, T.; Kato, M.; Suzuki, I. Magnetic Properties of Dimeric Copper(II) 2,2-Dimethylpropanoate. Bull. Chem. Soc. Jpn. 1986, 589, 3672-3674. [CrossRef] 